\title{
CS Research Square \\ Towards a Digital Health Curriculum for Health Workforce for the African Region
}

\section{Derrick Munene}

World Health Organisation Regional Office for Africa

Andrew Egwar Alunyu ( $\square$ aalunyu@gmail.com )

Makerere University College of Computing and Information Sciences https://orcid.org/0000-0003-2957-8423

Josephine Nabukenya

Makerere University College of Computing and Information Sciences

\section{Research article}

Keywords: Competence, Curriculum, Digital Health, eHealth, Health Worker, In-Service, Training

Posted Date: August 19th, 2019

DOI: https://doi.org/10.21203/rs.2.13130/v1

License: (c) (i) This work is licensed under a Creative Commons Attribution 4.0 International License. Read Full License 


\section{Abstract}

Background Digital technologies are fast gaining space in health. A skilled workforce is required to use existing and emerging technologies that support healthcare. However, existing medical informatics curriculum from the USA, UK, and African region reveal gaps in required competencies for a digital health worker, especially for the African region. Only a few health workers possess digital competencies required to optimally use existing technologies. Therefore, the aim of this study was to identify the need for and propose a structure of the digital health curriculum for the African region.Methods The study retrieved 42 peer-reviewed articles and reports published in English between 2005 and 2019 from PubMed Central, Google Scholar, and Biomedical Central. Only articles that addressed any form of pre-service and or in-service training of digital health workers were included in the review. In addition, 13 medical informatics curricula from the USA, UK, and African region were reviewed to determine the structure of the Digital Health curriculum suitable for the African region.Results Many countries in the African region have developed ehealth strategies that clearly highlight the need to train $\mathrm{DH}$ workforce. Results showed knowledge gaps of a communicator, a collaborator, a professional technologist, an advocate, and a manager required of digital health worker in the African region. However, existing digital/health informatics programmes in the region lack balanced course programmes to develop these core competencies. Besides, corresponding online training is modeled after traditional face-to-face training, thus limiting the opportunity for inservice health workers. Validation of the Lesotho curriculum confirmed only 10 modules as suitable to develop a rounded digital health worker (particularly for health leaders) for the African region.Conclusions Since it is important to develop competencies consistent with the local health systems to realize the full benefits of ehealth technologies, the African region needs to bridge their human resource gaps. Thus, African countries need to first develop or adopt a digital health worker competency framework and then re-organize their national health training curriculum to ensure a standardized / universal curriculum for training the digital health workforce. Future works will assess the DH worker competencies and expected outcomes for the African region.

\section{Background}

Digital health is considered to be an umbrella term encompassing eHealth and mHealth, as well as emerging and developing computing areas such as artificial intelligence and internet of things that support healthcare [1, 2]. Digital health technologies are widely referred to as ehealth technologies and present new or improved ways of delivering health care, conducting health promotion activities and monitoring public health [2, 3]. The technologies are geared toward meeting the growing demand for healthcare [3,4]. The human resources required to design, deploy, manage and/or use these technologies in support of healthcare need to be properly equipped with ICT skills [5]. They are categorised as health workforce skills, which include skills, experience, and knowledge to apply eHealth in the management and delivery of care to individuals and health ICT workforce, which include skills for design, building, operating and supporting eHealth services [6]. Thus, a diverse workforce herein referred to as Digital Health Worker, needs to be engaged holistically in order to develop, operate and support the national eHealth environment [6]. This workforce can be drawn from multiple professional backgrounds and diverse service providers [4]such as clinicians, health informatics professionals, IT professionals and professional managers [7], some of which lack the basic ICT skills required for them to fully use the digital tools and technologies at their disposal and to carry out their healthcare responsibilities. It takes the right professionals with the right combination of skills to work together to meet the challenges of obtaining data, make meaning and derive useful decisions from it. The social communication skills of digital natives differ from the type of information exchange required in healthcare [8]. In their study, Ahonen et al [9] pointed to the need for a multi-professional curriculum 
and a combination of trainable competencies for quality digital health and welfare service development. These are greatly lacking not only in the African region but across the world [10].

Academic institutions have continued to have traditional professional curricula without integrated formal coursework or clinical practice specific to using digital technologies for patient care in the professional curricula [8]. However, they lack the multi-professional requirement for a digital health worker skill in the use of digital technology to support healthcare. Consequently, Barakat et al [4], argue for education and training of healthcare professionals in the latest tools and methods to accelerate acceptance and use of digital technologies to collect, use and share information to support healthcare delivery. In addition, as more digital health technologies evolve health workers need more training to use them.

The term digital technology has also been defined as "... any product that can be used to create, view, distribute, modify, store, retrieve, transmit and receive information electronically in a digital form" [11]. Some of the digital health stakeholders are technology innovators, technology providers, and technology users, etc. The technology innovators provide the digital health tools and technologies for which the technology providers supply and / or provide, such as services to the technology users, who apply them or use them in their day-to-day healthcare services. The users need to participate to some extent in the design process. It should be realised that the technology users exist at all levels of the healthcare planning and service delivery including, strategic, tactical and operational [12]. In the African region, the strategic leve/ consists of the Permanent Secretary at the Ministry of Health, the Director General, Directors, Commissioners, and the Senior Management officials among others; the Tactical Level includes the National eHealth Director / Coordinator / eHealth Focal Person, ICT Manager, Local Government / District Management Team (e.g. District Health Officers), etc; while the Operational Leve/ has Doctors, Nurses, Laboratory technicians, Pharmacy Staff, Data entry clerks, IT administrators, etc. The technology users may use different technologies that require different competencies or may use the same technology with broad functionality but still require different levels of competencies. In addition to their professional knowledge, persons working at these three levels require specialised skills in using digital technologies to support healthcare. In fact, the World Health Organisation (WHO) suggest that training and education programmes will need to ensure that the workforce can use digital technologies proficiently in many settings, whether in the delivery of care (operational level), its management and administration (tactical level), or in health systems planning and management (strategic level) [3]. However, most of the health workforce, especially in the African region, lack core competencies that are required to use digital technologies. Thus, the benefits of digital health are not fully realised. Attaining a competent workforce is strained by limited or lack of capacity to develop and sustain such a workforce. Therefore, a curriculum is required to guide the required training of health workers in order to equip them with required competencies to implement, operate and use ehealth technologies [13]. The curriculum can be tailored to train pre-service or in-service health workers. Furthermore, training modules and online courses are suggested for digital health workers who may be remote from training institutions [3].

According to Lynott et al [14] current health systems training is not standardized and lacks content that may be required to address digital health worker needs. They identified the need for a training model that incorporates almost universal ehealth components like electronic health records. Therefore, there is a need to identify and structure the core competencies that a digital health worker should acquire to effectively use technology in support of healthcare services. In this regard, [15] argued for strengthening training programs for health workers to increase the number of qualified providers and hence improve health service quality.

\section{The African Region Digital Health Situation}


Besides the shortage of trained healthcare professionals working in Africa, less than $50 \%$ of Africans have access to good health facilities [16]. This situation can be improved by digital health technologies. Digital health can find broad applications in developing countries such as those in the African region, where the healthcare workforce and skills are limited. The healthcare service environment continues to experience challenges in the use of ICTs. However, these innovations are not matched to the requisite health worker usage skills [5]. The required ICT skills are needed and should be matched to appropriate Digital Health applications. These ICT applications include healthcare professional skills in mhealth services such as the use of mobile phones and wireless technology in public health education, supportive diagnostics, remote patient monitoring, data collection, helplines, etc., wearable technology/devices to track patient activities, personalised treatment, specific health issue monitoring, etc., and 3D printing in healthcare to produce a three dimensional solid objects like splints for children, 3D printed skin for burn victims. There are lack of skills among health workers for mHealth, eHealth, telehealth, health information technology, and telemedicine applications as well as wearable technologies, big data and use of artificial intelligence in healthcare [7]. The lack of skills exists also for the design, deployment, and management of digital health systems [5]. In fact, all the reviewed ehealth strategies for countries in the African region identified lack of skilled Digital Health (DH) workforce among the challenges to their ehealth strategic objectives $[13,17-$ 23]. One way to solve these gaps is by way of appropriate training of digital health workers.

Actually, countries across the African region are at different stages of implementation of Digital systems. They have identified the need to train a digital health workforce as one of the key components of their digital health programs [17-21]. The last survey on ehealth conducted in 2015/2016 in the region, showed that 18 out of 33 countries were offering pre-service training in ehealth, while 19 out of 33 countries were implementing ehealth capacity building for in-service health professionals [24]. From this survey, it is clear that countries in the African region lack trained health workers with the capacity to design, deploy and manage ehealth projects and programmes $[5,6]$. The lack of well-trained ICT professionals, insufficient awareness and experience in the use of ICTs remain important challenges to ehealth success in a developing country $[5,25]$. The problem is aggravated by limited opportunities for education in eHealth with most courses available only at the post-graduate level [19]. For example, Uganda's ehealth strategy expresses this as a deficit of adequate health informatics skills that need to be addressed [20]. Generally, the African region lacks a standard digital health curriculum to guide the training of the health workforce in the region; this poses a risk for fragmented and uncoordinated digital health skills workforce development. Workforce training are activities planned to make digital health knowledge and skills available through internal expertise, technical cooperation, or the private sector [26]. It includes establishing eHealth education and training programs for the digital health capacity building.

Largely, the above problem can be addressed through a mix of continuing education programmes like in-service training and pre-service training courses embedded in the main training curriculum as previously recommended [27]. Specialized ehealth technology training, short ehealth training programmes or online courses should be provided as part of continuing education for health workers; relevant ICT courses can be introduced in the curricula of all healthcare training institutions $[5,27]$. To address the lack of ICT skills among the digital health workforce, ITU's report on ICT for health recommends that a basic start is the adaption of medical students' curricula to include more courses about the new advancements of ICTs and eHealth [28]. Moreover one of the recommendations of the WHO World Health Assembly A71 resolution on digital health relates to health workforce development and skills in digital health, i.e. "to build, especially through digital means, capacity for human resources for digital health, as appropriate, across both health and technology sectors, and to communicate areas of specific need to the World Health Organization in order to receive appropriate technology assistance" [29].

Page $4 / 26$ 
Ultimately, to address this gap, some countries in the region such as Kenya, Ghana, Rwanda, South Africa, Uganda and Zambia among others embarked on implementing this resolution through the development of ehealth strategies. For example, Uganda's ehealth strategy identified the need to 'develop and enforce an eHealth Curriculum Framework to be followed by different training providers in developing and delivering Health training'[20]. A standardized structure for digital health worker curriculum is expected to produce professionals who can adapt to the fast-changing ehealth technological environment and thus, can work across the board.

According to McNay [30], as summarised in Alunyu et al [31], a curriculum can be considered to be a written plan of a degree programme, a syllabus, a course outline, a course study, a course guide, or a learning package. Thus, the digital health curriculum may be a dedicated bio medical/health informatics degree programme or syllabus [27], a course within medical professional pre-service training programme, a specialised ehealth technology study programme, a learning package for the in-service staff or an online ehealth technology training package which must be properly structured and documented. Whether they are in or outside the school, any planned training is considered part of a curriculum [32]. Consequently, this research paper focused on assessing the digital health (DH) worker learning needs and curriculum competencies in the African region, and to propose a structure for inservice health and ICT professional curriculum for the region. The proposed DH curriculum for the African region should be able to produce workforce both health and ICT that satisfy needs of the priority focus areas for ehealth highlighted in many of the human resource needs identified in the ehealth strategies of African countries. We thus discuss some of the current global $\mathrm{DH}$ training programmes with an aim to examine how these can easily be adopted for the African region and/or what adjustments and contextualisation should be made to suit the African region settings.

The rest of the paper is organized into sections that discuss the concept of the digital health worker, required competencies and curriculum; the methodology followed to generate the requirements for the digital health curriculum and guidelines for designing the curriculum; a discussion of the results on digital health training; and proposal of the structure of core competencies for the digital health worker curriculum for the African region as well as the Lesotho in-service (particularly health leaders) digital health worker curriculum for the African region and its validation. The paper concludes with recommendations for future work.

\section{The BioMedical/Health Informatics Training Curriculum}

In order to produce professionals with the required competencies to perform particular tasks, formal training institutions have used the model of a training curriculum. A curriculum outlines the what, how, why and when learning should happen, that is, a curriculum presents a structured plan for what contents to be delivered, how they should be delivered, the purpose for such training, and when to attain desired learning outcomes [32]. This learning process involves formal or informal interactions of the instructor (professional person) and the learner, personal initiatives of the learner, and or mentorship of a trainee.

The existing medical training curriculum offers formal and informal aspects of training. Whereas, informal training is unintended, i.e., can take place at any time or anywhere; formal training is guided by a structured curriculum. Although evaluating the quality of informal learning may be difficult, [33] argues that the quality of formal training is dependent on the quality of the curriculum. However, this author suggests that the quality of a curriculum should be judged in relation to the processes of curriculum development, implementation, and evaluation [33]. Therefore, to expect the quality of training from a digital health worker curriculum, the due process must be followed, that is, properly planned, consultative and inclusive development led by curriculum 
professionals, cyclical and sustainable. In this research, as a benchmark, we reviewed existing digital health curricula or programmes that offer components of Digital Health training to establish a basis for future digital health curriculum for the African region.

\section{Types of Training in the Healthcare Profession}

Commonly used modes of health worker training include pre-service training and continuing training [34], which were suggested by Asamoah-Odei, et al [5] as part of the systematic education for health workers in Digital Health. Pre-service training is the formal training provided by the health institution. Pre-service training introduces core skills much earlier to health workers especially during formal training [35]. It is integrated as part of the formal health education curricula. Continuing training embodies in-service training, refresher training, and or supportive supervision [36, 37]. In-service training or refresher training is training received by existing staff after their formal/initial professional training. The purpose of in-service is to acquaint employees with new skills, methods, procedures and or processes required to better their work performance [38]. Although in-service training is considered to be expensive requiring the trainees to leave their work places $[35,36]$, it is also considered to be very effective in healthcare cycles and has greatly facilitated the transfer to ICT-based work skills and routines among health professionals [39]. In addition, supportive supervision is sometimes recommended for healthcare in cases where help to improve staff work performance is tailored by using supervisory visits as opportunities to improve work knowledge and skills [37]. However, Asamoah-Odei, et al [5] argue that such systematic education must be at the heart of any strategy designed to facilitate ehealth. Therefore, the African region will reap the benefits of continuing training and pre-service training. Accordingly, with the need to develop or adopt diverse digital health training programmes such as the academic institutional DH curriculum, the GEEKS and I-LEAD programmes from the Centres for Disease Control (CDC) proposed learning exchange visits. These would provide support for (i) preservice training, (ii) conduct of in-service training to acquaint employees with new skills, methods, procedures and / or processes, and (iii) structured supportive supervision and sharing of expertise and experiences by digital health practitioners, hence providing broad learning opportunities for Digital Health workers.

As opposed to other training, healthcare training is very demanding and involves the use of humans as study subjects. Besides, new techniques, methods, procedures, and innovations are being frequently discovered or improved for the detection, treatment, and management of conditions, illness, and diseases that affect humanity [4]. To ensure the quality of service to patients/clients, practitioners need to acquaint themselves with these new innovations. Based on the principal objective of a quality curriculum by Stabback [33], the process of such acquaintance should be embedded as part of the healthcare training curriculum to streamline the development of practitioner's competencies (knowledge, skills, values, and associated capabilities) that make them professionally productive. Such inclusion is required for the new wave of digital health. If careful steps are taken, it may be suitably included in the in-service training curriculum for healthcare practitioners. This continuing education is crucial for quality improvement in healthcare [40]. In addition, Kyabayinze [41] argue for refresher training of new staff to fill gaps created by the high rate of staff turnover. Professional healthcare training continues throughout the life of a healthcare practitioner. Digital health worker training programmes can complement professional healthcare training to produce a competent digital health workforce. To achieve this, we explore competencies that qualify healthcare workers and discuss the need to impart similar competencies to a digital health worker.

Healthcare Professional Competencies 
This research used the CanMEDs framework [42], education model for equipping health professionals (with a focus on in-service personnel) with mHealth skills [8] and the European Digital Competence Framework [11, 43] to discuss the professional competencies required for healthcare personnel / health worker.

\section{The CanMEDS Framework}

The CanMEDS framework [42] has been widely used across countries to guide training in the different branches of medical education including nursing education [4]. The framework in supplementary Figure 1. online, stipulates six integrated sets of roles to qualify as a medical expert, which covers the medical knowledge, clinical skills, and professional attitudes in the provision of patient-centered care [42]. The competencies of a medical expert draw from the competencies of the roles of a communicator, collaborator, manager, health advocate, scholar and professional. In we summarise the key competencies for the different roles of a medical expert.

Table 1. Competencies of a Healthcare Professional

\begin{tabular}{|c|c|c|}
\hline Roles & Brief Description & Competencies \\
\hline Communicator & $\begin{array}{l}\text { - Communicator and a facilitator of the dynamic doctor- } \\
\text { patient relationship (before, during \& after the medical } \\
\text { encounter) }\end{array}$ & $\begin{array}{l}\text { - Communication skills to establish rapport \& trust } \\
\text { - Facilitation skills for shared decision-making \& plan of care }\end{array}$ \\
\hline Collaborator & $\begin{array}{l}\text { - Working in partnership with others involved in the care of } \\
\text { an individual/group }\end{array}$ & $\begin{array}{l}\text { - Effective collaboration skills } \\
\text { Domain knowledge/expertise }\end{array}$ \\
\hline Manager & $\begin{array}{l}\text { - Active engagement of all physicians as integral } \\
\text { participants in healthcare decision-making }\end{array}$ & $\begin{array}{l}\text { - Planning \& strategic thinking e.g. in resource allocation } \\
\text { - Problem-solving \& Decision-making }\end{array}$ \\
\hline $\begin{array}{l}\text { Health } \\
\text { Advocate }\end{array}$ & $\begin{array}{l}\text { - Use of activities to advance the health and well-being of } \\
\text { patients, communities, and populations }\end{array}$ & $\begin{array}{l}\text { - Health promotion } \\
\text {. Policy formulation }\end{array}$ \\
\hline Scholar & $\begin{array}{l}\text { A lifelong commitment to reflective learning, as well as } \\
\text { the creation, dissemination, application, and translation } \\
\text { of medical knowledge }\end{array}$ & $\begin{array}{l}\text { - Create, disseminate, apply and translate medical knowledge, } \\
\text { - Facilitate the education of their students, patients, colleagues, } \\
\text { and others. }\end{array}$ \\
\hline Professional & $\begin{array}{l}\text { - Dedication to health care of others } \\
\text { Mastery of a complex body of knowledge and skills, as } \\
\text { well as the art of medicine }\end{array}$ & $\begin{array}{l}\text { - Clinical competence } \\
\text { - Code of ethics - appropriate attitudes and behaviors, integrity, } \\
\text { altruism, personal well-being, and to the promotion of the public } \\
\text { good within their domain }\end{array}$ \\
\hline
\end{tabular}

In training a digital health worker, we argue that since they provide services that support healthcare, their learning outcomes should be aligned to most of the roles of a medical expert in the CanMEDS framework. In addition, use of Digital Health technologies does not exempt healthcare workers and professionals at all the levels (strategic, tactical, and operational) of the healthcare system from utilizing the competencies developed by the CanMEDS framework. In fact, if properly used, the technologies aid their skills in communication, collaboration, decisionmaking, clinical competence, and health promotion among others, to advance care and wellbeing for all.

\section{Education Model for Equipping Health Professionals with mHealth Skills}

Slovensky et al [8] proposed a model for preparing health professionals (with professional clinical knowledge and skills) in the deployment and use of mHealth interventions. Their model presents five key knowledge areas in the preparation of a health professional to use biomedical and communication technologies including digital 
communication skills, technology literacy, and usage skills, deploying telehealth products and services, regulatory and compliance issues, and telehealth business case (see supplementary Figure 2 online). In addition, they highlight the need to address organizational issues especially as part of in-service training and collaborations. The organizational context in the African region consists of the country's health system including both the public and private healthcare institutions. The required skills for a digital health worker at the organization may vary depending on the type of digital technologies adopted by the organization. In addition, as membership to the DH workforce is drawn from different professional backgrounds, with varying skills, they require tailor-made induction or in-service training to prepare them for optimal use of the digital health technologies at work.

Thus, in their model for preparing health professionals (with clinical knowledge and associated technical skills) to deploy mHealth, Slovensky et al [8] identified the following as required core competencies for a digital health worker,

- Digital communication skills are provided to acquaint the health worker in the use of various digital communication technologies in a rapidly changing communication environment. Unlike basic communication skills that can be outlined in a simple document, digital communication is a behavioral skill best learned through the application, feedback, and practice [8] and impacts the encounter in an examination room [14].

- Technology literacy and usage skills are required for the digital health worker to use digital technologies and more so, know when to use technology to support healthcare. Rather than the technologies replacing human function in healthcare, it should complement humans such as in-patient consultation.

- Deploying telehealth products and services requires a proper understanding of the technology in addition to using technology to manage multiple stakeholders, policies and organizational

- The health workers must understand the regulatory and compliance issues since they work with personal information regulated by the legislation. The organizational context such as the African region's health systems should have patient health information sharing guidelines that the digital health worker needs to learn and follow in addition to any other technology compliance regulations.

- Understanding the telehealth business case is required for a digital health worker to appreciate both the clinical and business perspectives for better outcomes. A proper understanding of the business case can enable the digital health worker to recommend a viable case of digital health intervention for the organization.

The model focuses on professionals with an assumed clinical/professional body of knowledge and skills but lacking some or all of the aforementioned body of knowledge/skills to deploy and use mHealth. In this respect, we recommend the model's suitability to be applied to the training of in-service healthcare professionals especially in the African region where healthcare professionals lack the required ehealth competencies in addition to low levels of basic ICT skills.

\section{The European Digital Competence Framework}

The European digital competency framework $[11,43]$ highlights the major areas of any digital competence, which we associate with the needed competency for a digital health worker including;

- Competency in information and data literacy enables the digital health worker to identify, locate and retrieve relevant health information in addition to storing and managing them in a digital format. 
- Communication and collaboration competency enables the use of ehealth technologies to interact, exchange information, engaging in citizenship, and collaborate netiquette and managing the digital identity of clients.

- Handling of healthcare digital content includes creation and management. Data (clinical, referral, care, patient historical data among others) contributes a greater percentage to the digital content created in a healthcare The need for big data analytics (mining) was previously predicted as important skills for the future (the present) informaticians [44]. Therefore, the present and future digital health worker needs skills in big data analytics including an understanding of how to make improvement and integrate information and content into an existing body of healthcare knowledge while following applicable copyright and licenses (authorization) procedures.

- A digital health worker with privacy and safety skills can appropriately enforce protection of digital devices, personal data, and privacy measures. It also covers health protection and wellbeing in addition to protecting the environment.

- Problem-solving competency allows the digital worker to identify digital technology needs and gaps and creatively use digital technologies to solve technical problems. The digital health worker needs to keep to-date with the digital evolution. In addition, competency in problem-solving includes improving/modifying existing solutions in new problem contexts, troubleshooting complex issues that require ehealth technological innovations or even troubleshooting and fixing problems in the technologies. Unlike the European context where expertise is readily available, in the African context the responsibility to fix minor failures e.g., destination unreachable due to the unpowered access point in a facility setting may belong to the health worker.

These competencies would be suitable for the African region; however, limited health worker ICT literacy and usage skills, and digital communication skills among others, challenge them. In order to bridge such gaps, we integrate competencies from the Education Model for Equipping Health Professionals with mHealth Skills [8] and The European digital competency framework $[11,43]$ to guide the training of the digital health worker's branch of medical education as per the CanMEDs framework [42] as recommended by [4] (see supplementary Figure 3 Online).

Furthermore, Mantas et al [27] recommend for developing countries to adapt the required knowledge, skills, and competencies with regard to the level of technology. In this regard, we consider competencies for a digital health worker and categorize them (see supplementary Figure 3 online) according to the roles of the CanMEDS framework for a health professional. These are the key components of the training programme, which may guide the structure of the training programme course outlines. The programme course content is aimed at imparting knowledge/skill to the trainees; hence prepare an all-round digital health worker. We develop upon the three domain areas of methods and technologies for healthcare data processing, medical sciences, and health system organization and informatics as recommended by International Medical Informatics Association as highlighted by [44] to meet the expectations of a digital health worker. These expectations include being a good communicator, a collaborator, a professional, an advocate and a manager, analyst of the big health data generated, protect the security and privacy of health data/information in their care and is able to fix minor failures in the technologies they are using. It should be realized that the required levels of competencies might vary according to the expectations of the work position. Some of the training may only be basic/foundational, intermediary, advanced or even specialized / expert [43]. 
Although Spiget et al[45] identified the content and the duration of the training programme as major considerations in effective training to increase technology literacy regarding the security of mHealth devices and technologies, we argue that any training programme's content and duration are key contributors (among others) to the success of such training.

\section{Methods}

A literature review was conducted from PubMed Central, Google Scholar, and Biomedical Central. We also searched websites of medical training institutions and ministries of health websites for ehealth curricula and ehealth strategies respectively. The following keywords/phrases were used to retrieve relevant documents used in the review: 'electronic health', 'curriculum' and 'health worker'. To exhaust the search, keywords like electronic health were exchanged with digital health, ehealth, e-health, mobile health, mHealth and $\mathrm{m}$-health; curriculum with the training programme, learning package, syllabus and course of study; and health worker with a healthcare worker, a medical worker, and medical staff. In searching for relevant articles from the databases, our search strategy involved the use of the Boolean AND/OR for keyword combinations.

Inclusion/exclusion criteria: Articles were included in this review if they addressed any type of health worker preservice training or any form of continuing education (in-service training) in the use of ICT, ehealth technologies (including mHealth, telemedicine, health information systems, among others) to support healthcare. Also included in the review are ehealth strategies and various ehealth academic programmes. We included only those articles published in English language literature. Articles that lacked consideration for digital health worker skills training component and those that generally focused on medical worker training without attention to equipping them for the digital environment were excluded.

In this review, only 63 documents were included in the reporting after the screening of originally identified 1,233 non-duplicate records that met the search criteria and applying the exclusion criteria as seen in supplementary Figure 4 online. The records include 42 peer review documents and reports on ehealth/digital health human resource capacity needs, digital competency, and health worker training from WHO and regional governments like the European Union, East African community among others; 13 health/medical informatics training curriculum; and 08 national ehealth strategies.

\section{Results And Discussion}

As more digital technologies continue to diffuse into the healthcare systems, in-service training remains a suitable option for professionals who have already obtained a professional qualification. Whether it is a formal curriculum for medical schools or training programme for in-service professionals, they need to produce competent digital health workers. By competent, we mean the digital health worker is capable of using a wide range of ehealth technologies in new or improved ways to deliver healthcare, conduct health promotion activities and monitor public health [2]. According to Hersh et al [46], it is important to identify and develop competencies consistent with the local health systems that are needed to realize the full benefits of ehealth technologies. On this basis, we reviewed human resource (capacity building) needs to be expressed by the ehealth strategies of eight African countries. They all expressed the need to develop digital health competencies. These countries are representative of advancement in ehealth among the Anglophone countries. They have developed ehealth strategies that clearly highlight the need to train DH workforce. Besides they are making efforts towards a national implementation of 
ehealth. The review revealed similar, but broad knowledge gaps/challenges across the African continent (see Table 2).

Table 2. Human resource needs for ehealth as identified by ehealth strategies of five African countries [13, 17-23] 


\begin{tabular}{|c|c|c|}
\hline Country & eHealth knowledge gaps/challenges & Recommendations \\
\hline Kenya & $\begin{array}{l}\text { - Expertise in eHealth applications } \\
\text { - Skills needed to use and maintain eHealth } \\
\text { systems } \\
\text { - Technical knowledge to support other } \\
\text { users of ehealth system }\end{array}$ & $\begin{array}{l}\text { - Develop \& incorporate a universal curriculum in IT training in health training } \\
\text { institutions } \\
\text { - Capacity building / online \& change management training }\end{array}$ \\
\hline Uganda & $\begin{array}{l}\text { - Insufficient biomedical/medical } \\
\text { informatics experts and trained ICT } \\
\text { professionals } \\
\text { - Inadequate integration of eHealth skills } \\
\text { into existing health professional training } \\
\text { curricula } \\
\text { - Inadequate awareness of electronic } \\
\text { information security and privacy measures }\end{array}$ & $\begin{array}{l}\text { - Conduct digital health worker training and skills need assessment } \\
\text { - Develop, adopt or adapt eHealth skills and competencies framework } \\
\text { - Develop \& enforce eHealth Curriculum Framework } \\
\text { - Conduct Personal Information Privacy training and awareness }\end{array}$ \\
\hline Ghana & $\begin{array}{l}\text { - Low levels of computer literacy / low } \\
\text { adaptation to current ICT trend } \\
\text { - Very limited exposure to ICT during } \\
\text { training } \\
\text { - Lack of professional training in the } \\
\text { management of ehealth } \\
\text { - ICT capacity building is directed to use } \\
\text { training in the use of applications, not } \\
\text { technical skills }\end{array}$ & $\begin{array}{l}\text { - Include basic practical ICT skills in systems that support e-health } \\
\text { - Define a standardized e-health competency framework for health workers and health } \\
\text { sector information technology practitioners } \\
\text { - Embed e-health into their continuing education curricula } \\
\text { - Grant access to electronic course materials and to indexed health literature }\end{array}$ \\
\hline Malawi & $\begin{array}{l}\text { - Lack of professional competency in } \\
\text { ehealth } \\
\text { - Lack of accredited educational programme } \\
\text { and or training courses in ehealth } \\
\text { - Lack of in-country tailored online } \\
\text { educational or training programme, } \\
\text { especially for in-service personnel }\end{array}$ & $\begin{array}{l}\text { - Define a standardized ehealth competency framework for health workers } \\
\text { - Determine the education and training courses suitable for the development of ehealth } \\
\text { workforce capabilities } \\
\text { - Establish a national qualification in health informatics for formal training and embed } \\
\text { ehealth into the training curricula of post-secondary educational institutions } \\
\text { - Collaboration with training institutions to develop, implement and deliver online } \\
\text { training in ehealth }\end{array}$ \\
\hline Nigeria & $\begin{array}{l}\text { - Inadequate workforce to develop, use and } \\
\text { maintain Health ICT } \\
\text { - Lack of method for accreditation/revision } \\
\text { of health ICT training curriculum } \\
\text {-Lack of clear career paths for Health ICT } \\
\text { professionals }\end{array}$ & $\begin{array}{l}\text {-Empower the workforce to develop, use and maintain Health ICT } \\
\text {-Develop incentive mechanisms to encourage workforce development of Health ICT } \\
\text { skills } \\
\text {-Establish a methodology for accreditation and revision of Health ICT training } \\
\text { Curriculum } \\
\text {-Establish special Health ICT education, training and career paths }\end{array}$ \\
\hline $\begin{array}{l}\text { South } \\
\text { Africa }\end{array}$ & $\begin{array}{l}\text { - No standardized eHealth competency } \\
\text { framework for health workers and health IT } \\
\text { practitioners } \\
\text { - Limited or no workforce to innovate, } \\
\text { develop, deploy, maintain and support all } \\
\text { eHealth interventions }\end{array}$ & $\begin{array}{l}\text { - Establish a standardized competency framework for digital health workers } \\
\text { - Train more professionals to innovate, develop deploy, maintain and support all ehealth } \\
\text { interventions }\end{array}$ \\
\hline Tanzania & $\begin{array}{l}\text { - Limited basic ICT training for health } \\
\text { workers } \\
\text { - Lack of ehealth training curriculum } \\
\text { - Lack of online learning platform / digital } \\
\text { materials that support ehealth education }\end{array}$ & $\begin{array}{l}\text { - Develop and approve a methodology for delivering blended learning, including basic } \\
\text { ICT training for health workers. } \\
\text { - Develop an ehealth education or training curriculum/program for various health } \\
\text { workers. } \\
\text { - Implement health sector elearning platform. } \\
\text { - Develop digital resources to enable offline learning for areas with limited Internet } \\
\text { access along with online learning. }\end{array}$ \\
\hline Zambia & $\begin{array}{l}\text { - Lack of ICT skills in healthcare training } \\
\text { programmes } \\
\text { - Low levels of ehealth practitioners }\end{array}$ & $\begin{array}{l}\text { - Include ICT in the pre-service training curriculum, in-service, task shifting of ICT tasks } \\
\text { - Integration of all existing eHealth curricula for modular and cadre-based training, e.g., } \\
\text { implement changes to vocational and tertiary training programs for the increasing }\end{array}$ \\
\hline
\end{tabular}


In order to bridge these human resource gaps, the African countries need to first develop a digital health worker competency framework and then re-organize their national health training curriculum to ensure a standardized / universal ehealth curriculum. Thereafter, the digital health worker can acquire the necessary skills and knowledge in the areas of basic IT, ehealth technology use, technical support and security measures needed to optimize the use of ehealth technologies. To achieve the objectives of technology to deliver healthcare, the interest may be on "how to use" ICT to deliver better healthcare; to conduct health promote, there may be need to understand "ways in which" ICT can be used as a leverage to promote health; and to monitor health, the focus may be on "ways to use" ehealth technologies as a media to monitor public health.

In order to attain the understanding of how to use, ways in which and ways to use, authors have identified competencies that the different professions may bring to the digital health (i.e., ehealth, mHealth, telehealth, electronic records, etc.) and may be instilled in the digital health worker including but not limited to basic IT literacy, communication skills, healthcare physician, management and development, IT guidance/support, range of DH technologies, information privacy and confidentiality, biomedical/health informatics, among others $[4,9$, 47]. In a Delphi-study of competencies required for nursing telehealth activities, Van Houwelingen et al[48] identified knowledge (clinical, procedure, telehealth, laws and regulations, etc), attitudes, general analytical and privacy skills, technological skills, clinical skills, communication skills, and implementation skills. These competencies cut across nursing professional work and those required for the use of digital technology to support nursing function, enhancing their ability to combine nursing experience into digital health.

Overview of digital health worker training programmes: assessment of required competencies

Following the revolutionizing effort to digitize healthcare across the globe, health workers adapt the use of enabling technologies in their provision of care. In recognition of the need for healthcare professionals to be digitally competent, the European countries have taken steps to provide the required training/learning in the use of ehealth technologies to health workers [10,43]. A review of how some of the existing DH curriculum/training programmes in the USA, UK, and African countries are geared towards developing the core DH competencies is summarised in Table 3. They can be categorised to develop competencies in bioinformatics, public health informatics, organizational informatics, social informatics, and clinical informatics.

An assessment of health informatics competencies in undergraduate programmes at the University of Rwanda, identified only ICT literacy and use skills, informatics terminology and digital communication as most present [49]. Regards training of a digital health worker for the African region, the following common themes/gaps exists in producing a communicator, a collaborator, a professional technologist, an advocate, and a manager.

(i) Short training courses are tailored to develop crucial/urgent competencies for a target group. Example of the Farr Institute[1] besides technical training, embedded professional skills such as communication, leadership, influencing ability and decision making into its training courses.

(ii) Most programmes lack courses to develop the core competencies required for a digital health worker, e.g., technology literacy and use, digital communications, security, and Although configuration and programming had a large number of courses, they do not focus on issues critical to the successful implementation of digital health in 
Africa; issues such as establishing communication medium for uploading digital data, setting up security measures inbuilt in the digital technologies, etc. Hence, courses should be tailored to develop these competencies, which are desirable for the African region.

(iii) Although some of the programmes are online/distance-learning programmes, most of those in the African region is modeled after the traditional face-to-face training limiting the opportunity for in-service health worker from becoming a digital health worker. It may be beneficial to introduce online or distance learning programmes to cater for these group of workers in addition to supporting the introduction of new technology or boosting refresher training programmes. The mode of delivery affects the worker's desire to engage in training. Besides workers in the healthcare sector are faced with personnel shortage, hence their high workload limits the time required to engage in continuing education.

\section{[1] http://farrinstitute.org/research-education/education}

Table 3. Course distribution for Digital health worker competencies in selected curriculum/training programmes from the USA, Europe, and African regions

\begin{tabular}{|c|c|c|c|c|c|c|c|c|c|c|c|}
\hline \multirow[t]{2}{*}{ Digital Health Worker Training Programme } & \multicolumn{11}{|c|}{ \# of courses developing the competencies } \\
\hline & A & $\mathrm{B}$ & C & D & $\mathrm{E}$ & $\mathrm{F}$ & G & $\mathrm{H}$ & $\mathrm{I}$ & $\mathrm{J}$ & $\mathrm{K}$ \\
\hline Digital Health Systems, University of Strathclyde, Glasgow[1] & 0 & 0 & 1 & 0 & 1 & 0 & 2 & 0 & 2 & 1 & 1 \\
\hline Health Informatics, The University of Sheffield[2] & 0 & 0 & 2 & 0 & 0 & 1 & 0 & 0 & 2 & 1 & 1 \\
\hline Health Informatics, University College London[3] & 1 & 1 & 2 & 1 & 1 & 0 & 1 & 1 & 1 & 1 & 2 \\
\hline Master in Interdisciplinary Data Science, Duke Center for Health Informatics[4] & 0 & 1 & 0 & 0 & 0 & 0 & 2 & 0 & 4 & 0 & 3 \\
\hline Electronic Health Records Management, Ashworth College[5] & 0 & 1 & 2 & 3 & 2 & 1 & 0 & 0 & 1 & 3 & 0 \\
\hline BSc in Health Information Management, East Carolina University[6] & 1 & 0 & 3 & 3 & 4 & 3 & 1 & 1 & 2 & 6 & 3 \\
\hline \multirow[t]{2}{*}{ Biomedical and Health Informatics, The University of North Carolina at Chapel Hill[7] } & 0 & 1 & 4 & 0 & 1 & 5 & 6 & 0 & 8 & 2 & 1 \\
\hline & 0 & 1 & 2 & 2 & 1 & 5 & 5 & 0 & 5 & 0 & 1 \\
\hline $\begin{array}{l}\text { MSc. in Applied Health Sciences Informatics, Johns Hopkins School of Medicine, Division of } \\
\text { Health Sciences Informatics [8] }\end{array}$ & 2 & 0 & 2 & 5 & 1 & 3 & 1 & 1 & 2 & 4 & 16 \\
\hline MEASURE Evaluation [9] & 0 & 0 & 2 & 1 & 0 & 0 & 0 & 1 & 1 & 1 & 0 \\
\hline Medical Informatics, University of KWAZULU-NATAL[10] & 1 & 0 & 0 & 3 & 2 & 2 & 1 & 0 & 2 & 1 & 0 \\
\hline Masters in Health Informatics, University of Ghana[11] & 1 & 0 & 2 & 1 & 1 & 0 & 5 & 1 & 8 & 3 & 2 \\
\hline \multirow[t]{2}{*}{ Masters in Health Informatics, Makerere University[12] } & 1 & 0 & 1 & 1 & 1 & 3 & 2 & 2 & 2 & 5 & 2 \\
\hline & 1 & 0 & 1 & 1 & 1 & 3 & 0 & 0 & 3 & 7 & 2 \\
\hline MSc. Health Informatics, University of DAR ES SALAAM[13] & 4 & 0 & 0 & 1 & 2 & 2 & 3 & 2 & 4 & 3 & 3 \\
\hline
\end{tabular}

Notes: Assessment of course distribution per competency / knowledge area in existence in some of the existing digital health worker curriculum/training programmes across the USA, UK, and the African region. $\mathrm{A}=$ Technology literacy \& usage skills; $\mathrm{B}=\mathrm{Digital}$ communication; $\mathrm{C}=$ Deploying ehealth; D = Products \& services; E = Regulation \& compliance (implementation); F = eHealth business case; $G=$ Configuration \& Programming; H = Security and privacy; I = Data Handling; $\mathrm{J}=$ Healthcare introduction \& terminologies; and $\mathrm{K}=$ Practicum \& Research Methods.

[1] https://www.strath.ac.uk/courses/postgraduatetaught/digitalhealthsystems/

[2] https://www.sheffield.ac.uk/postgraduate/taught/courses/

[3] https://www.ucl.ac.uk/health-informatics/study/postgraduate-taught-programmes/health-informatics-msc 
[5] https://www.ashworthcollege.edu/career-diplomas/electronic-health-records-management/curriculum/

[6] http://www.ecu.edu/cs-dhs/hsim/bs_him/index.cfm

[7] https://chip.unc.edu/mps-bmhi-curriculum/

[8] https://www.hopkinsmedicine.org/som/students/graduate-programs/welcome/programs.html

[9] https://www.measureevaluation.org/resources/health-informatics-for-low-and-middle-income-countries-short-course-for-health-informationsystem-professionals

[10] http://is.ukzn.ac.za/Courses/medicalinformatics.aspx

[11] http://www.ug.edu.gh/biostats/courses?field_department_tid=5

[12] http://www.musph.ac.ug/index.php/accordion-2/152-mhi

[13] http://cse.udsm.ac.tz/index.php/programmes/postgraduate/msc-health-informatics

(iv) Limited or non-existent courses to provide specialized training in the deployment and / or use of ehealth technologies. The curriculum needs to provide for various specialized training in existing and emerging ehealth technologies such as DHIS2, EHR, EMR, PHR, and MHealth applications. For example, in Uganda, a single medical records officer may have to work with a wide range of systems like EHR, DHIS2, etc., in addition to providing technical support, use of HR systems, connecting and reconfiguring the facility WIFI, etc.

(v) Although data handling has more courses, the reviewed programmes excluded content on block chain technology, which is one of the emerging technologies that ensure the integrity of digital data content.

Furthermore, existing courses focus largely on data analytics than security and privacy, which is quite essential to health data. Security and privacy courses are completely missing in most of the programmes.

(vi) The existing training programmes/curricula lack a common structure for preparing digital health workers. While some had more courses, others had less for a particular digital competency area implying products from different training institutions/programmes may possess varying levels of proficiency. There is therefore urgent need to develop a standardized digital health worker curriculum or re-structure existing ones so as to produce comprehensively skilled digital health workers for the African region. In addition, equipping of digital health workers across the board with similar skills will enhance cross boarder ehealth information exchange for the purposes of consulting and healthcare management.

(vii) The concentration of programmes and/or courses on developing particular competencies with little to no regard for other core competencies as exemplified by most full academic training curricula. Thus, regardless of whether it is the University College London programmes in health informatics, health data science, and health data analytics or Makerere University health informatics programme, they all focus on developing limited Digital Health worker competencies. This may be wanting for the African region where the need is for a broad set of competencies.

Based on the gaps above, this study proposes a structure for the standard digital health worker-training curriculum for the African region. 
The Digital Health (DH) curriculum for the African region should produce workers that satisfy personnel needs of the priority areas for ehealth highlighted in many of the African countries' ehealth strategies. However, the African region is characterized by multiple but distributed implementations of ehealth/digital technologies, thus require digital health workers (health managers and leaders, clinicians, physicians, nurses, pharmacists, information technologists, human resource officers, etc.) with diverse competencies to use them.

This study's assessment of the existing curricula across the globe helped to establish the DH curriculum trends, and thus determined what is suitable or what can be contextualised/customised for the African region with further adoption. In Table 4 and Table 5 respectively, are summaries for structures of the standard DH pre-service and inservice curricula for the African region. Although studies have suggested that digital health worker training is incorporated into the standardized medical training curriculum $[4,10,50]$, others advocated for training at the workplace (i.e. in-service training) [10]. Both approaches provide a suitable training environment for pre-service trainees and in-service professionals respectively.

Whereas the in-service training curriculum in Table 5 is aimed to prepare digital health leaders in their work practices; the Pre-service training curriculum in Table 4 is based on a benchmark of the different types of DH worker curricula competencies across the globe, the digital health worker needs of the African region and core competencies required of any digital health worker. In fact, there are calls to fill knowledge and skills gaps for health workers using ICT to support healthcare [13, 17-23]. The competency framework is derived from the CanMEDS framework [42], the education model for equipping health professionals with mHealth skills [8], and the European digital competency framework $2.0[11,43]$. presents a summary of the proposed knowledge areas and competencies by levels of proficiencies that a DH Worker curriculum for the Africa region should have.

Table 4. Digital Health Worker Competencies for the African Region: Pre-service Training Curriculum 


\begin{tabular}{|c|c|c|c|c|}
\hline $\begin{array}{l}\text { Levels of } \\
\text { proficiency }\end{array}$ & Level 1 - Basic & Level 2 - Intermediate & Level 3- Advanced & Level 4 - Expert \\
\hline $\begin{array}{l}\text { Brief } \\
\text { description }\end{array}$ & $\begin{array}{l}\text { This is foundational \& } \\
\text { develops the digital health } \\
\text { worker's literacy level. } \\
\text { Provides common } \\
\text { knowledge or } \\
\text { understanding of basic } \\
\text { ehealth technology } \\
\text { techniques and concepts } \\
\text { e.g., types of technology, } \\
\text { purpose, how to use, etc. } \\
\text { Key terms include use, } \\
\text { find, identify, etc. }\end{array}$ & $\begin{array}{l}\text { Training at this level aims } \\
\text { at developing the digital } \\
\text { health worker capability to } \\
\text { independently use ehealth } \\
\text { technology to complete } \\
\text { tasks and to apply ehealth } \\
\text { technology knowledge or } \\
\text { skill in different situations. } \\
\text { Key terms include explain, } \\
\text { describe, illustrate, among } \\
\text { others. }\end{array}$ & $\begin{array}{l}\text { Advanced training equips } \\
\text { the digital health worker } \\
\text { with techniques to apply } \\
\text { theory. Can perform } \\
\text { ehealth technology tasks } \\
\text { without help, it's a level of } \\
\text { ehealth technology } \\
\text { professionalism. Key } \\
\text { terms include apply, show, } \\
\text { propose, explain, vary, } \\
\text { assess, etc. }\end{array}$ & $\begin{array}{l}\text { This level prepares a digital } \\
\text { health worker to provide } \\
\text { guidance on specific ehealth } \\
\text { technology(ies), troubleshoot } \\
\text { and answer questions related to } \\
\text { them or an area of expertise } \\
\text { within the technology. The digital } \\
\text { health worker becomes the } \\
\text { consultant - "go to person" Key } \\
\text { terms include create, integrate, } \\
\text { propose, etc. }\end{array}$ \\
\hline $\begin{array}{l}\text { Expected } \\
\text { Outcomes }\end{array}$ & \begin{tabular}{|l} 
- \\
identify medical \\
informatics / ehealth \\
terminologies, concepts, \\
principles, and issues \\
- Can utilize a full range \\
of ehealth technologies
\end{tabular} & $\begin{array}{l}\text { - Occasionally apply } \\
\text { knowledge to different } \\
\text { cases with minimal } \\
\text { guidance } \\
\text { - Understand and can } \\
\text { discuss the application } \\
\text { and implications of } \\
\text { ehealth technology } \\
\text { changes to processes, } \\
\text { policies, and procedures } \\
\text { - Chooses appropriate } \\
\text { tools for tasks } \\
\text { - Experiments with new } \\
\text { processes, tools, or } \\
\text { technologies to determine } \\
\text { the applicability }\end{array}$ & $\begin{array}{l}\text { - Provide } \\
\text { practical/relevant ideas } \\
\text { and perspectives on } \\
\text { ehealth technology } \\
\text { processes or practice } \\
\text { improvements to be } \\
\text { implemented } \\
\text { - Coach others in the } \\
\text { application of ehealth } \\
\text { technologies translating } \\
\text { complex problems to } \\
\text { solvable forms } \\
\text { - Support the ehealth } \\
\text { technology } \\
\text { development process } \\
\text { including references and } \\
\text { resource materials } \\
\end{array}$ & $\begin{array}{l}\text { - Demonstrate consistent } \\
\text { excellence in applying ehealth } \\
\text { technology expertise across } \\
\text { multiple projects and/or health } \\
\text { systems } \\
\text { - Create new } \\
\text { technologies/application } \\
\text { scenarios } \\
\text { - Explain the relevant ehealth } \\
\text { technology process elements } \\
\text { and issues in relation to } \\
\text { organizational issues and } \\
\text { trends in sufficient detail }\end{array}$ \\
\hline $\begin{array}{l}\text { Possible } \\
\text { competencies }\end{array}$ & $\begin{array}{l}\text { - Can use computers \& } \\
\text { other ICTs } \\
\text { - Can identify appropriate } \\
\text { ehealth technologies } \\
\text { - } \text { Browse, search, filter } \\
\text { data, information, and } \\
\text { digital content } \\
\text { - Distinguish data, } \\
\text { information and digital } \\
\text { content } \\
\text { - Can understand ehealth } \\
\text { \& medical terminologies; } \\
\text { identify diseases codes, } \\
\text { etc. } \\
\text { - Can use inbuilt security } \\
\text { measures }\end{array}$ & $\begin{array}{l}\text { In addition to level } 1 \\
\text { competencies, can; } \\
-\quad \text { Evaluating data, } \\
\text { information and digital } \\
\text { content } \\
-\quad \text { Managing data, } \\
\text { information and digital } \\
\text { content } \\
-\quad \text { Interact through digital } \\
\text { technologies } \\
- \text { Share through digital } \\
\text { technologies } \\
-\quad \text { Engage in citizenship } \\
\text { through digital } \\
\text { technologies } \\
- \text { Collaborate through } \\
\text { digital technologies } \\
-\quad \text { Netiquette } \\
-\quad \text { Managing digital identity } \\
\end{array}$ & \begin{tabular}{|l} 
In addition to level 2 \\
competencies, level 3 \\
digital health worker can; \\
- $\quad$ Develop ehealth content \\
- Integrate and re- \\
elaborate on the ehealth \\
digital content \\
$-\quad$ Solve technical but \\
ehealth related problems \\
$-\quad$ Shares expertise, \\
teaching skills and \\
explaining concepts to \\
others \\
$-\quad$ Copyright and licenses
\end{tabular} & $\begin{array}{l}\text { In addition to level } 3 \\
\text { competencies, level } 4 \text { digital } \\
\text { health worker can; } \\
-\quad \text { Improve or redesign ehealth } \\
\text { processes, tools or technology } \\
-\quad \text { Implement and troubleshoot } \\
\text { complex issues on ehealth } \\
\text { technology(ies) of their } \\
\text { expertise } \\
-\quad \text { Programming }\end{array}$ \\
\hline $\begin{array}{l}\text { Possible } \\
\text { competency } \\
\text { categories }\end{array}$ & 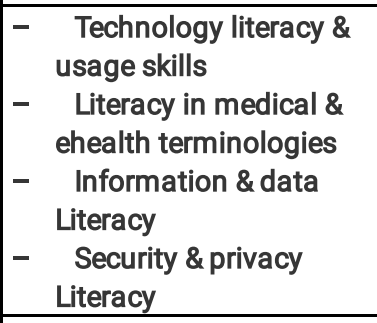 & \begin{tabular}{|c} 
In addition to level 1 \\
competency categories are; \\
- $\quad$ Digital communication \\
eHealth products \& \\
services
\end{tabular} & \begin{tabular}{|l} 
In addition to level 2 \\
categorization; \\
$-\quad$ Regulation \& \\
compliance \\
(implementation) \\
$-\quad$ Business processes
\end{tabular} & \begin{tabular}{|c} 
In addition to level 3 \\
categorization; \\
$-\quad$ Networking and \\
Programming \\
$-\quad$ Data analytics
\end{tabular} \\
\hline \multirow{2}{*}{$\begin{array}{l}\text { Example of } \\
\text { security \& } \\
\text { Privacy } \\
\text { application }\end{array}$} & \multicolumn{4}{|c|}{ 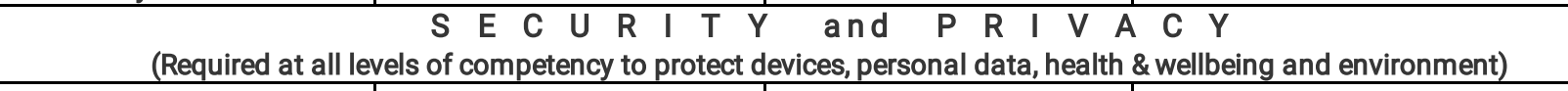 } \\
\hline & $\begin{array}{l}\text { Protect devices, use } \\
\text { security measures on } \\
\text { devices \& inside } \\
\text { applications, etc; }\end{array}$ & \begin{tabular}{|l|} 
Protect devices, use \\
security measures on \\
devices, inside applications, \\
on data/information \\
sharing, etc
\end{tabular} & $\begin{array}{l}\text { Protect \& guide others on } \\
\text { how to protect devices, } \\
\text { applications, } \\
\text { data/information privacy, } \\
\text { etc }\end{array}$ & $\begin{array}{l}\text { Improve or develop systems to } \\
\text { enforce security \& privacy }\end{array}$ \\
\hline
\end{tabular}


Table 5. Digital Health Worker Competencies for the African Region: In-service Training Curriculum

\begin{tabular}{|c|c|c|c|c|c|c|c|}
\hline $\begin{array}{l}\text { Integrated } \\
\text { Digital } \\
\text { Health } \\
\text { Building } \\
\text { steps }\end{array}$ & $\begin{array}{l}\text { Understanding } \\
\text { Digital Health }\end{array}$ & $\begin{array}{l}\text { National } \\
\text { Strategy } \\
\text { Development }\end{array}$ & \begin{tabular}{|l|} 
Digital Health \\
Interventions \\
identification \\
and \\
Requirements \\
Analysis \\
\end{tabular} & \begin{tabular}{|l|} 
Digital Health \\
Platform and \\
Applications Design
\end{tabular} & $\begin{array}{l}\text { Development, } \\
\text { Deployment, } \\
\text { Maintenance } \\
\text { and Scale Up }\end{array}$ & \begin{tabular}{|l} 
Data Use \& \\
Analytics
\end{tabular} & $\begin{array}{l}\text { Monitoring \& } \\
\text { Evaluation }\end{array}$ \\
\hline \begin{tabular}{|l|} 
Training \\
Modules
\end{tabular} & $\begin{array}{l}\text { Module 1: } \\
\text { Introduction to } \\
\text { digital health } \\
\text { - Digital Health } \\
\text { Systems and } \\
\text { Service } \\
\text { - Health } \\
\text { System } \\
\text { Building Blocks } \\
\text { - Digital Health } \\
\text { Solution } \\
\text { - Value of } \\
\text { Digital Health } \\
\text { \& } \\
\text { Transformative } \\
\text { Role of Digital } \\
\text { Health }\end{array}$ & $\begin{array}{l}\text { Module 2: } \\
\text { Digital } \\
\text { Health } \\
\text { Strategy, } \\
\text { Governance } \\
\text { \& } \\
\text { Regulations } \\
\text { Develop a } \\
\text { national } \\
\text { digital } \\
\text { health } \\
\text { strategy } \\
\text { outlining } \\
\text { overarching } \\
\text { needs, } \\
\text { desired } \\
\text { activities, } \\
\text { and } \\
\text { outcomes } \\
- \text { Formulate } \\
\text { a digital } \\
\text { health } \\
\text { investment } \\
\text { plan to } \\
\text { support the } \\
\text { national } \\
\text { strategy } \\
\text { Establishing } \\
\text { a } \\
\text { governance } \\
\text { mechanism }\end{array}$ & $\begin{array}{l}\text { Module 6: } \\
\text { Implementing } \\
\text { Digital Health } \\
- \\
\text { Requirements } \\
\text { Gatherin } \\
-\quad \text { Technology } \\
\text { Invento } \\
-\quad \text { Determining } \\
\text { ICT } \\
\text { functionalities } \\
\text { to address } \\
\text { needs: } \\
\text { Prioritizing } \\
\text { Digital Health } \\
\text { Intervention } \\
\text { - Costing } \\
\text { - Project } \\
\text { Management } \\
\text { \&Planning } \\
\text { - Stakeholder } \\
\text { Engagement } \\
\text { - Human } \\
\text { Centered } \\
\text { Design }\end{array}$ & $\begin{array}{l}\text { Module 4: Digital } \\
\text { Health Global Goods } \\
\text { Applications } \\
- \\
\text { OpenMRS/OpenClinic, } \\
\text { iHRIS, OpenLMIS, } \\
\text { RapidPro, OpenSRP, } \\
\text { Open Deliver, } \\
\text { Telemedicine, } \\
\text { OpenELIS, openIMIS } \\
\text { Module 7: Digital } \\
\text { Health Architecture } \\
\text { Design } \\
- \text { Business } \\
\text { Architecture } \\
- \text { Information } \\
\text { Architecture } \\
-\quad \text { Digital Platform } \\
\text { infostructure } \\
- \text { OpenHIE as an } \\
\text { example of a health } \\
\text { information } \\
\text { architecture }\end{array}$ & $\begin{array}{l}\text { Module 6: } \\
\text { Implementing } \\
\text { Digital Health } \\
- \text { Digital } \\
\text { Health } \\
\text { Deployment } \\
-\quad \text { RFP } \\
\text { development }\end{array}$ & $\begin{array}{l}\text { Module 10:Data } \\
\text { use and } \\
\text { Analytics } \\
- \text { Techniques for } \\
\text { information } \\
\text { needs } \\
\text { assessment } \\
-\quad \text { Principles of } \\
\text { data harvesting } \\
-\quad \text { Data } \\
\text { Visualization \& } \\
\text { Information } \\
\text { Communication } \\
-\quad \text { Data related } \\
\text { Regulation }\end{array}$ & $\begin{array}{l}\text { Module 9: } \\
\text { Monitoring, } \\
\text { Learning and } \\
\text { Evaluation } \\
- \text { Why and how- } \\
\text { M\&E } \\
- \text { Global toolkits- } \\
\text { When and how } \\
\text { to use? } \\
- \text { Continuous } \\
\text { improvement } \\
- \text { Adapt and } \\
\text { accomplish } \\
- \text { Assessing and } \\
\text { monitoring } \\
\text { implementation }\end{array}$ \\
\hline
\end{tabular}

Regards the in-service training curriculum, it is guided by the recommendation of the Nigeria ehealth strategy that suggests the need for a nationally scaled health and ICT workforce education/training in addition to incorporating Health ICT into standardized curricula [18]. Table 5 presents a summary of the in-service training curricular for the African region. It is based on the DH leadership curriculum that was designed, executed and validated in Lesotho and assumes that health leaders at the strategic and tactical levels of the healthcare system require 
knowledge/skills in the use of digital technologies to support their strategic and tactical decision-making. In this curriculum, the ten modules as shown in Table 5 aim to prepare the DH leader to understand the concept of digital health and how it can influence the development of national strategies; identify $\mathrm{DH}$ interventions and requirements; design DH platform and applications; develop, deploy, maintain and scale up of DH; use and analyse health data; and finally how to monitor and evaluate DH systems.

The first three modules, i.e. 1-3 provide the underlying principles/foundations to understanding the concept of digital health and how it influences the national strategy development. The three modules do introduce the digital health systems and services and their key components that include strategy, governance, and regulations. To better understand the concept of digital health, the Maternal and Child Health (MNCH) and Non-Communicable Diseases (NCDs) are used as examples to explain and demonstrate how digital health can be applied in the health system.

Modules 4, 7 and 8 provide an overview of digital health platforms and application designs. Particularly module 4 summarizes the Global Goods and their applications including OpenMRS/Open Clinic, iHRIS, OpenLMIS, RapidPro, OpenSRP, Open Deliver, and Telemedicine among others. Global Goods are digital health applications that can be used in various countries across the globe irrespective of health system settings. Module 7 specifically describes the digital health architecture design including the business architecture, data architecture, applications architecture and digital platform infostructure, for which the OpenHIE is used as an example of health information architecture. Module 8 lays out the interoperability frameworks and highlights the standards and profile stacks for developing interoperability frameworks in varying health systems in the African region.

Module 5 then introduces the development, deployment, maintenance and scale up of digital health applications. This module explains how to implement digital health applications and infostructure, and how to ensure its sustainability. It further explains the relationships between partnership models such as health and IT industry e.g. the telecommunications and how they can support digital health in the health sector.

Module 6 provides a summary of digital health interventions identification, requirements analysis, and deployment standards. The module particularly describes the requirements gathering, technology inventory, Request for Proposal (RFP) development and determining ICT functionalities to address needs, prioritizing digital health interventions viz-a-viz costing, project management \& planning, stakeholder engagement, and human-centered design.

Module 9 explains the monitoring, learning and evaluation components of digital health systems. The module entails an understanding of how to assess and continuously improve the maturity of Health Information Systems (HIS) to achieve better health outcomes. It further explains why and how Monitoring \& Evaluation (M\&E) is done, when and how to use global toolkits, continuous improvements in M\&E including standards for assessing and monitoring implementation.

Module 10 deals with data use and analytics. This included how to use data and basic regulations governing data access and use. It also discusses related issues such as techniques for information needs assessment, principles of data harvesting and data visualization and information communication and a broad summary on data-related regulations and policies among others.

\section{Conclusion}


In this work, we reviewed the current state of the digital health worker curriculum across the globe with the aim to develop a standard DH training curriculum for the African region. The study assessed various DH worker-training curricula across the globe in order to identify the digital health worker learning needs and required competencies for the African region. The review showed limited core competencies and lack of common curricula structure across existing digital health worker training programmes. There was also limited focus on the entire life span of the digital health ecosystem. We used relevant health worker training frameworks/models and digital competency frameworks to develop a competency framework for the $\mathrm{DH}$ worker curriculum. The assessment of existing curricula across the globe helped to establish the DH curriculum trends, and thus determine what is a recommended curriculum for the African region. We expect the DH curriculum to fill the digital health worker competency gaps that currently exist within the African region. Our future work points to the need to re-assess the key DH worker competencies and expected outcomes for the African region once the in-service curriculum have been implemented, and the evaluation to adopt the use of ehealth technologies in support of decision-making and management at strategic and tactical levels, and its success have been completed.

\section{Abbreviations}

DH: Digital Health; DHIS2: District Health Information Systems - 2; HER: Electronic Health Records; EMR:

Electronic Medical Records; PHR: Personal Health Record; CDC: Centres for Disease Control; MNCH: Maternal and Child Health; NCD: Non-Communicable Disease; HR: Human Resources; ICT: Information and Communication Technology; ITU: International Telecommunication Union; M\&E: Measurement and Evaluation; and WHO AFRO: World Health Organisation, Regional Office for Africa.

\section{Declarations}

Ethics Approval and Consent to Participate

Not applicable.

Consent for Publication

The authors consent to the publication of this study by BMC Medical Informatics and Decision

Making.

Availability of data and material

The materials/articles used in this review are available upon request from the corresponding author.

Competing Interests

The authors declare that they have no competing interests.

Funding

Not applicable.

Author's Contributions 
DM and JN conceived the idea. Then, AAE and JN collaborated on the protocol, read abstracts and selected papers for the review. Also, AAE and JN selected and assessed existing curricula/training programmes from the USA, Europe, and African regions. All authors (DM, AAE and JN) reviewed documents listed as references and developed the full manuscript.

\section{Acknowledgements}

We acknowledge the WHO-AFRO and ITU for initiating the digital health capacity building for health leaders in the African region, where $\mathrm{DM}$ and $\mathrm{JN}$ conceived the idea of conducting a systematic review in order to scientifically ground the Digital Health Worker curriculum.

\section{References}

1. World Health Organisation. mHealth Use of appropriate digital technologies for public health. 2018. doi:10.1371/journal.pmed.1001362.

2. Lupton D. Critical perspectives on digital health technologies. Sociology Compass. 2014;8:1344-59.

3. World Health Organisation. WHO/HIS/SDS/2018.55 Digital technologies: shaping the future of primary health care. Geneva; 2018. https://www.who.int/docs/default-source/primary-health-care-conference/digitaltechnologies.pdf?sfvrsn=3efc47e0_2. Accessed 27 Mar 2019.

4. Barakat A, Woolrych RD, Sixsmith A, Kearns WD, Kort HS. eHealth Technology Competencies for Health Professionals Working in Home Care to Support Older Adults to Age in Place: Outcomes of a Two-Day Collaborative Workshop. 2013. doi:10.2196/med20.2711.

5. Asamoah-Odei E, Kebede D, Zielinski C, Soumbey-Alley E, Peixoto M, Moeti M. Leveraging eHealth to improve national health systems in the African region. Afr Health Monit. 2012;:46-52.

6. World Health Organization \& International Telecommunication Union. National eHealth strategy toolkit. International Telecommunication Union; 2012. http://www.who.int/iris/handle/10665/75211. Accessed 24 Nov 2018.

7. Steen L, Mao X. Digital skills for health professionals. In: Re-thinking european healthcare: Recommendations by the next generation. Euopean Health Parliament; 2016. p. 37-47.

8. Slovensky DJ, Malvey DM, Neigel AR. A model for mHealth skills training for clinicians: meeting the future now. 2017;3. https://www.ncbi.nlm.nih.gov/pmc/articles/PMC5505927/.

9. Ahonen O, Rajalahti E, Tana J, Lejonqvist GB, Kinnunen UM, Saranto K. Developing Digital Health and Welfare Services in an International Multidisciplinary Student Team. MEDINFO 2017: Precision Healthcare through Informatics. 2017;:679-83.

10. European Commission. eHealth Action Plan 2012-2020. Innovative healthcare for the 21 st century. Communication from the commission to the European parliament, the council, the European economic and social committee and the committee of the regions Brussels, 612 2012. 2012.

11. Vuorikari R, Punie Y, Carretero S, Van den Brande. DigComp 2.0, we present now eight profciency levels and examples of use applied to the learning and employment feld. EU Science Hub. 2016. https://ec.europa.eu/jrc/en/digcomp/digital-competence-framework. Accessed 7 Nov 2018.

12. Hans EW, Van Houdenhoven M, Hulshof PJ. A framework for healthcare planning and control. In: Handbook of healthcare system scheduling. Springer, 2012. p. 303-320. 
13. Kenya Ministry of Health. Kenya National eHealth Policy 2016-2030. 2017.

14. Lynott MH, Kooienga SA, Stewart VT. Communication and the electronic health record training: a comparison of three healthcare systems. Journal of Innovation in Health Informatics. 2013;20:7-12.

15. Diedhiou A, Gilroy KE, Cox CM, Duncan L, Koumtingue D, Pacqué-Margolis S, et al. Successful mlearning pilot in senegal: delivering family planning refresher training using interactive voice response and SMS. Global Health: Science and Practice. 2015;:ghsp14-00220.

16. Clausen LB. Taking on the Challenges of Health Care in Africa | Stanford Graduate School of Business. Insights by Stanford Business. 2015.

17. Ghana Ministry of Health. Ghana National eHealth Strategy. 2010.

18. Nigeria Ministry of Health. National Health ICT Strategic Framework 2015-2020. 2016.

19. South Africa, Ministry of Health. Natonal eHealth Strategy, South Africa 2012/13-2016/17. 2012.

20. Uganda Ministry of Health. Uganda National eHealth Strategy and Policies. 2016.

21. Zambia Ministry of Health. eHealth Strategy 2017 - 2021. 2017.

22. Malawi, Ministry of Health. The Malawi National eHealth Strategy. 2014. https://www.who.int/goe/policies/malawi_ehealth_strategy2011_2016.pdf. Accessed 26 Mar 2019.

23. Tanzania, Ministry of Health. Tanzania National eHealth Strategy 2012 - 2018. 2013. https://www.who.int/goe/policies/countries/tza_ehealth.pdf.

24. WHO \& ITU. Atlas of eHealth country profiles 2015: The use of eHealth in support of universal health coverage. WHO. 2015. http://www.who.int/goe/publications/atlas_2015/en/. Accessed 28 Feb 2019.

25. Salifu Y, SOAR J. Preparedness for e-Health in developing countries: the case of Ghana. Journal of Health Informatics in Developing Countries. 2014;8.

26. East African Health Research Commission. Digital REACH Initiative Roadmap: Digital Regional East African Community Health Initiative. 2017.

27. Mantas J, Ammenwerth E, Demiris G, Hasman A, Haux R, Hersh W, et al. Recommendations of the International Medical Informatics Association (IMIA) on education in biomedical and health informatics. Methods of information in medicine. 2010;49:105-120.

28. Stolyar V, Amcheslavskaya M. Remote Interactive Training for Doctors Based On Video Conference Solutions, In Question 2/2: Information and telecommunications/ICTs for ehealth, Study Period 2014-2017, ITU (or International Telecommunication Union). Geneva, Switzerland; 2017. p. 102-4.

29. World Health Organisation. WHA71.7 Agenda Item 12.4: Digital health. 2018. http://apps.who.int/gb/ebwha/pdf_files/WHA71/A71_R7-en.pdf.

30. McNay M. Western guide to curriculum review. Western University, Teaching Support Centre; 2009.

31. Alunyu AE, Nabukenya J. A Conceptual Model for Adaptation of eHealth Standards by Low and MiddleIncome Countries. J Health Inform Afr. 2018;5:10-6.

32. Hunkins FP, Ornstein AC. Curriculum: Foundations, principles, and issues. Pearson Education; 2016.

33. Stabback P. What Makes a Quality Curriculum? UNESCO IBE. 2016;2:2-41.

34. van Gemert-Pijnen J, Wynchank S, Covvey HD, Ossebaard HC. Improving the credibility of electronic health technologies. Bulletin of the World Health Organization. 2012;90:323-323A.

35. World Health Organization. The World Health Report 2006 - working together for health. WHO. 2006. https://www.who.int/whr/2006/en/. Accessed 3 Nov 2018. 
36. Bluestone J, Johnson P, Fullerton J, Carr C, Alderman J, BonTempo J. Effective in-service training design and delivery: evidence from an integrative literature review. Human resources for health. 2013;11:51.

37. O'Donovan J, O'Donovan C, Kuhn I, Sachs SE, Niall W. Ongoing training of community health workers in lowincome and middle-income countries: a systematic scoping review of the literature I BMJ Open. BMJ Open. 2018;8. doi:10.1136/bmjopen-2017-021467.

38. Funes R, Hausman V, Rastegar A, Bhatia P. Preparing the next generation of community health workers: the power of technology for training. Iheed Institute; 2012.

39. OECD. Country Indicators. 2010. doi:10.1787/data-00378-en.

40. Gaspard J, Yang C-M. Training needs assessment of health care professionals in a developing country: the example of Saint Lucia. BMC medical education. 2016;16:112.

41. Kyabayinze DJ, Asiimwe C, Nakanjako D, Nabakooza J, Bajabaite M, Strachan C, et al. Programme level implementation of malaria rapid diagnostic tests (RDTs) use: outcomes and cost of training health workers at lower level health care facilities in Uganda. BMC Public Health. 2012;12:291.

42. Frank JR. The CanMEDS 2005 physician competency framework. http://rcpsc medical org/canmeds/CanMEDS2005/CanMEDS2005_e pdf. 2005.

43. Carretero S, Vuorikari R, Punie Y. DigComp 2.1: The Digital Competence Framework for Citizens with eight profciency levels and examples of use. 2017.

44. Huang QR. Competencies for graduate curricula in health, medical and biomedical informatics: a framework. Health Informatics Journal. 2007;13:89-103.

45. Spigel L, Wambugu S, Villella C. mHealth Data Security, Privacy, and Confidentiality: Guidelines for Program Implementers and Policymakers. MEASURE Evaluation, University of North Carolina; 2018.

46. Hersh W, Margolis A, Quirós F, Otero P. Building a health informatics workforce in developing countries. Health Affairs. 2010;29:274-277.

47. Fisk M. Necessary Skills and Knowledge for Staff Providing Telehealth Services. Jordanova M and Lievens F (Eds) Global Telemedicine and eHealth Updates: Knowledge Resources. International Society for Telemedicine and eHealth; 2014.

48. van Houwelingen CT, Moerman AH, Ettema RG, Kort HS, ten Cate O. Competencies required for nursing telehealth activities: A Delphi-study. Nurse education today. 2016;39:50-62.

49. Nishimwe A, Mbarushimana V, Nyssen M. Assessment of Health Informatcs Competencies in Undergraduate Training of Healthcare Professionals in Rwanda. Rwanda Journal Series F: Medicine and Health Sciences. 2016;3:36-41.

50. Pathipati AS, Azad TD, Jethwani K. Telemedical education: training digital natives in telemedicine. Journal of medical Internet research. 2016;18.

\section{Figures}




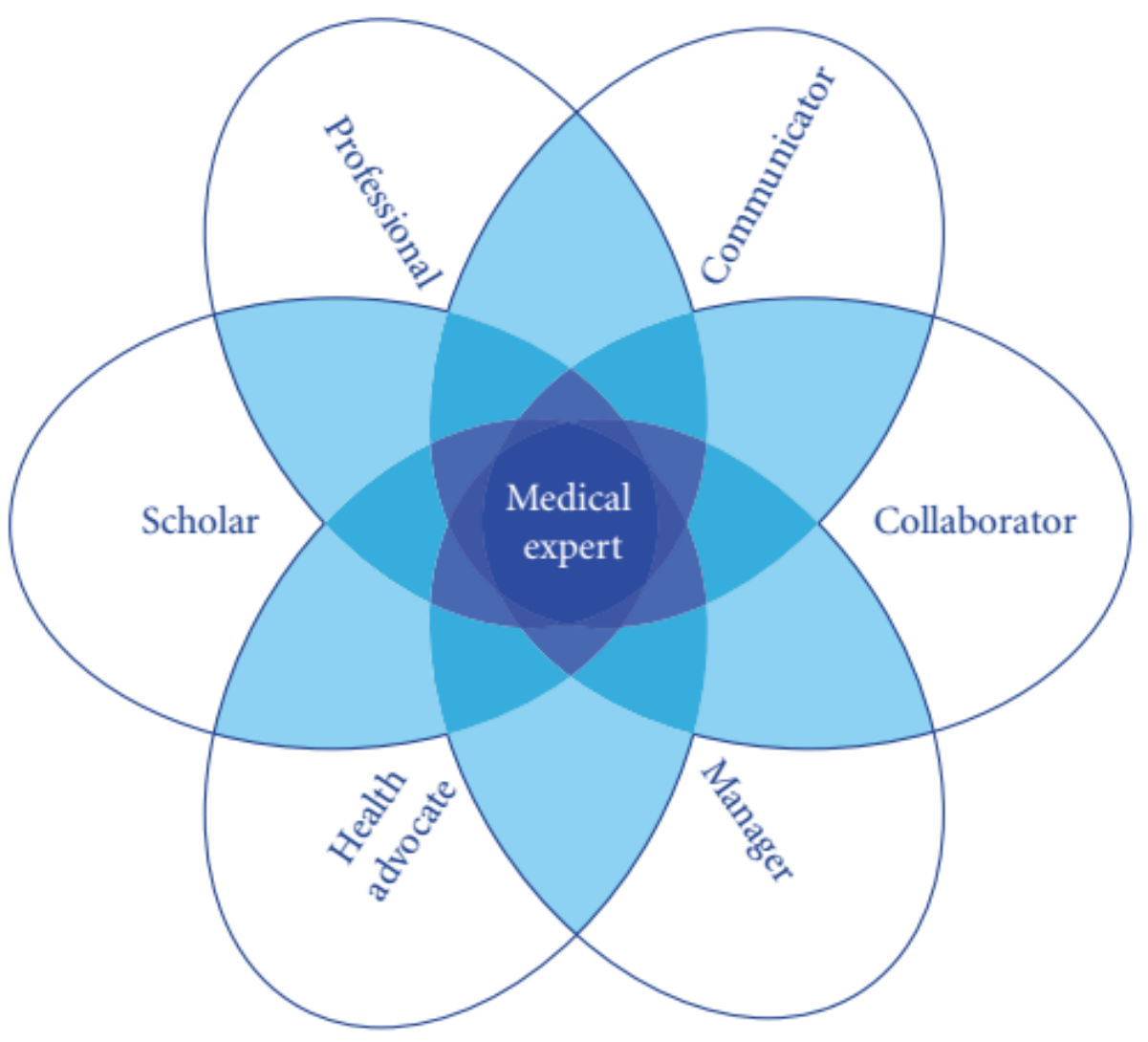

Figure 1

The CanMEDS Roles Framework

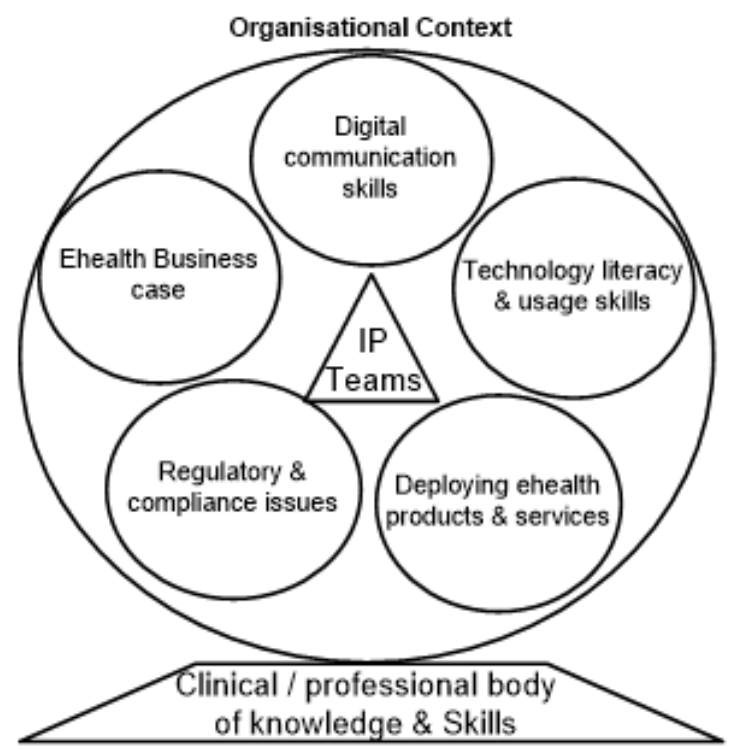

Figure 2

Education Model for Equipping Health Professionals with m(e)Health Skills 


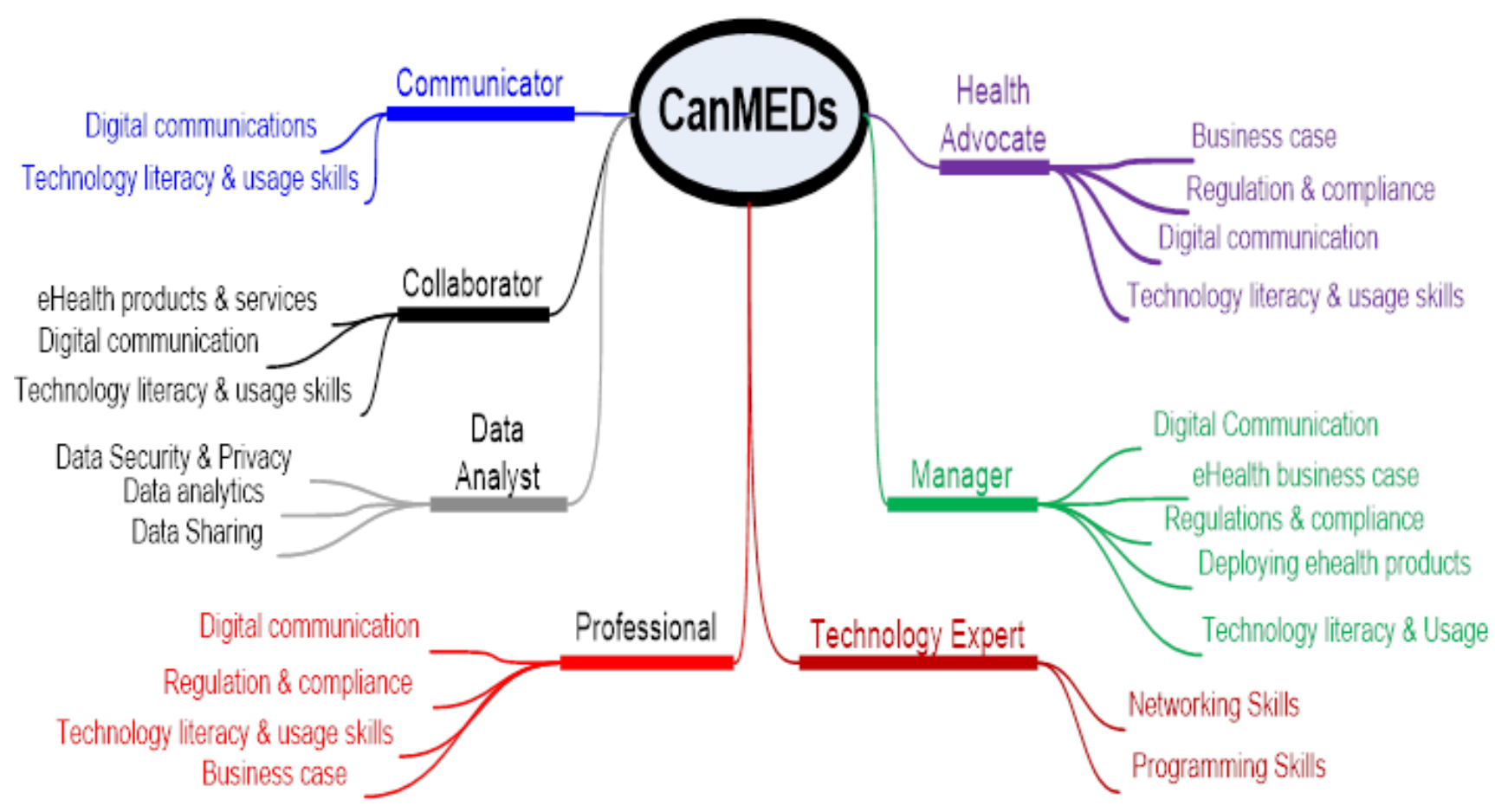

Figure 3

Proposed Learning Requirements for a Digital Health worker for the African Region

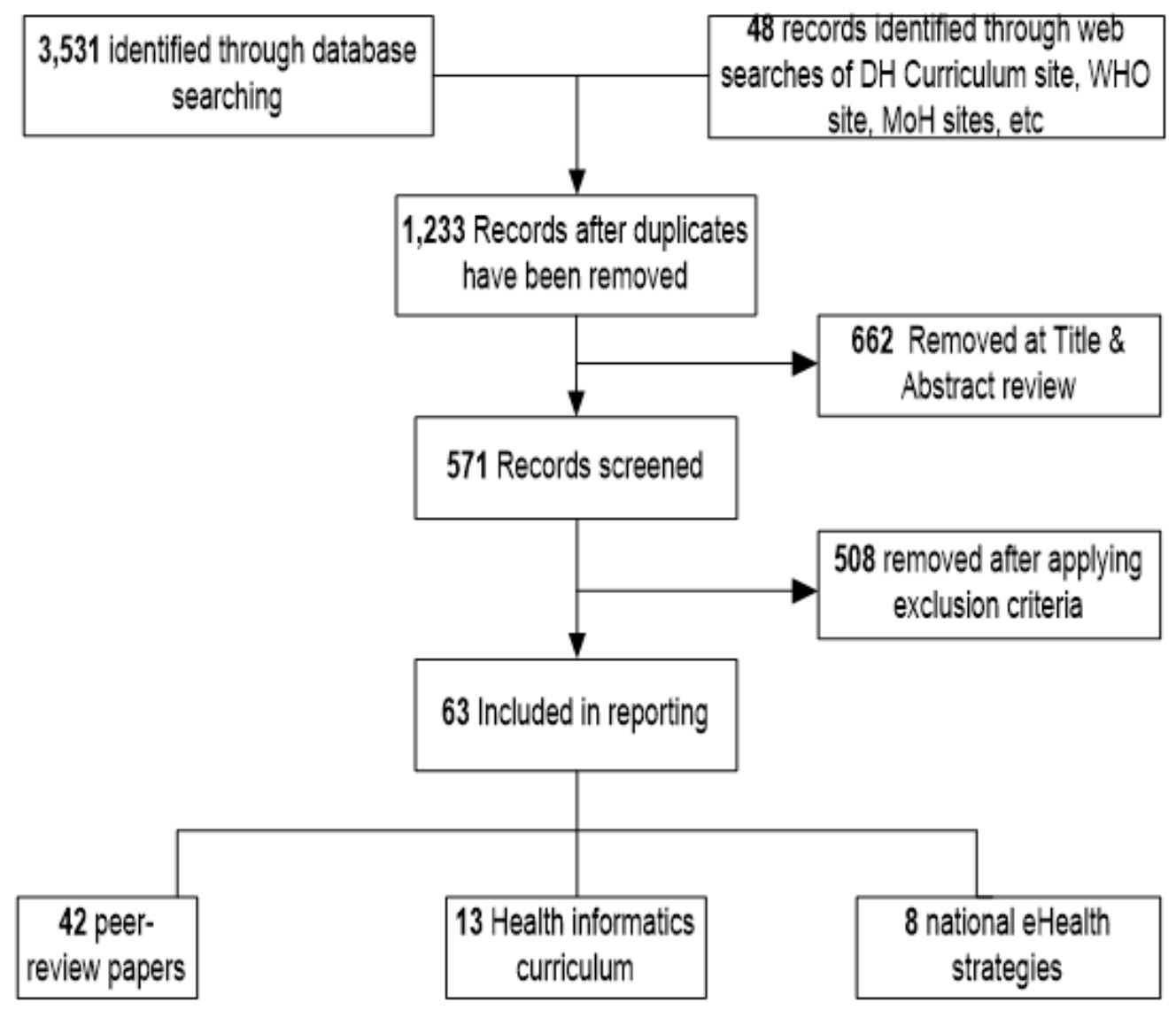

Figure 4 
Flow-chart showing the search strategy and inclusion/exclusion criteria 